\title{
Experimental research steel grade «Steel 45» to abrasion wear, depending on the exit angle macrostructure fibers on the contact surface
}

\author{
Maksim Gennadievich Allenov, ${ }^{1,}$, Dmitrii Gennadievich Allenov ${ }^{2}$, and Oleg Aleksandrovich Belokurov ${ }^{1}$ \\ ${ }^{1}$ BMSTU, Engineering Technology Department, 105005 Baumanskaya 2-ya str. 5 Moscow, Russia \\ ${ }^{2}$ RUDN University, Engineering academy, 117198 Miklukho-Maklaya str. 6 Moscow, Russia
}

\begin{abstract}
This paper describes the experimental research of the influence of the angle of exit of microstructure fibers to the contact surface wear abrasion steel grade «steel 45». The experimental dependence of abrasion wear depending on output angle of macrostructure fibers to the contact surface was obtained (considered angles: $0^{\circ}, 15^{\circ}, 30^{\circ}, 45^{\circ}, 60^{\circ}, 75^{\circ}, 90^{\circ}$ ). A method for obtaining samples with a specified directional fiber structure was development. Two experiments were carried out: on a friction machine of translational type and on a friction rotational type machine. The article shows the difference in wear with different types of friction: rotation motion simulates wear in bearings, translational motion simulates the movement of the piston in the cylinder or the operation of the guides. The effect of the exit angle of the macrostructure fibers on wear is determined. An analysis of the experimental data was carried out and the angles of the yield of fibers on the contact surface were found at which maximum and minimum wear was attained.
\end{abstract}

\section{Introduction}

The fibrous composition of the metal macrostructure is obtained from the ingots dendritic structure contaminated with nonmetallic inclusions, during casting and subsequent processing by pressure. Fibers macrostructures are stretched in the direction of the most intense flow of the metal. This macro-structure cannot be eliminated by thermal treatment. The distribution of macrostructure fibers is detected by etching on the macrostructure, after which they are visible to the naked eye.

In the metal with the fibrous composition of the macrostructure, anisotropy of the mechanical properties is observed depending on the direction of the fibers. Similarly, the anisotropy of mechanical properties affects wear on the abraded surfaces as a result of contact with other parts [1]. This effect is observed in the work of friction pairs, for example, in an internal combustion engine (shafts, root and conrod necks, etc.). On the faculty of "Technology of pressure treatment" (MT-6) MSTU. N.E. Bauman was studied the creation of a directed fibrous structure of the macrostructure in forgings of critical details [2,3]. A study of abrasion wear as a function of the yield angle of the macrostructure fibers to the contact surface was carried out [4]. However, no study of abrasion wear with modern types of oils including antiwear and antifriction additives was carried out. In addition, we investigated the effect only at 3 different exit angles of the fiber on the working surface $\left(0^{0}, 45^{\circ}, 90^{\circ}\right)$, which does not allow to determine the increase in the operability of the obtained parts in the process of designing the forging process, depending on the yield angle of the macrostructure fibers on working surfaces. When stamping forgings, most often, the exit angle of the macrostructure fibers on the working surface is in a certain range, and does not have a definite value.

Therefore, an experimental study of the effect of the exit angle of macrostructure fibers with a small step on abrasive wear is an urgent task in the development of technological pro-cesses of hot forging. Earlier, in the article [5], the influence of the exit angle fiber in the translational motion of friction particles was considered.

\section{Research methodology}

In this paper, we studied the effect of the exit angle of the macrostructure fibers on the contact surface in step of 15 degrees on the abrasive wear on the abrasion of steel 45. A special friction machine of translational and rotational type was used to study abrasive wear (Fig. 1, Fig. 2).

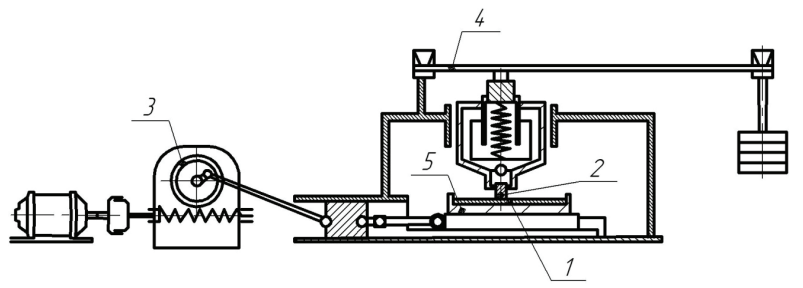

Fig. 1. Friction machine of the translational type: $1-$ lower sample; 2 - upper sample (pin); 3 - crank mechanism; 4 - level device; 5 - bath for oil.

\footnotetext{
* Corresponding author: okdell@mail.ru
} 
The operating principle of the friction machine of the translational type (Fig. 1): the upper sample 2 is pressed by the lever device 4 to the self-adjusting slide bar on which the lower sample 1 is located. The slide moves reciprocally from the crank mechanism 3 . The length of the samples can vary from 30 to $70 \mathrm{~mm}$; the maximum number of double strokes per minute is 47 . The load varies in the range from 100 to $3000 \mathrm{~N}$. A self-adjusting sample that provides running-in both initial and after intermediate weighing, facilitates work of the machine. Tests can be carried out in a variety of liquid fluid, since the sample can be placed in a bath 5 .

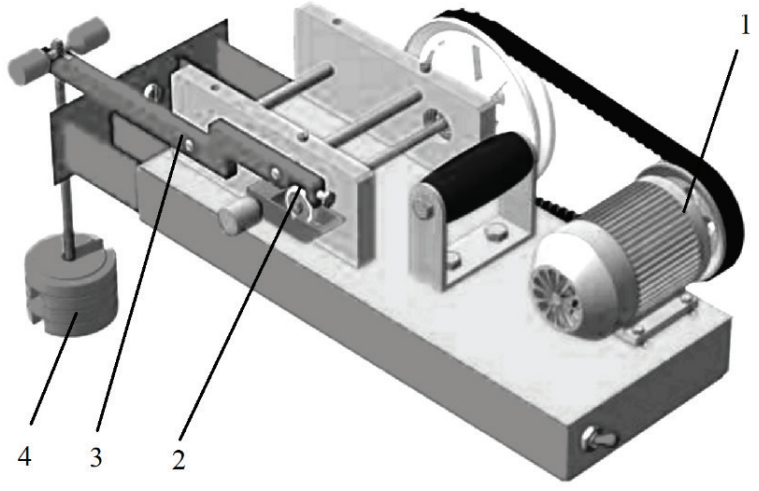

Fig. 2. Friction machine of the rotation type: 1 - electric motor; 2 - friction unit with bath for oil; 3 - level device; 4 - loads.

The principle of operation of the rotational type of friction machine (Fig. 2) is as follows: The electric motor drives 1 the disc in the friction unit 2 via a belt driving. The upper sample is pressed by the lever device 3 to the rotating disk by means of loads 4 . There is also an oil bath in the friction unit. Rotational speed is 400 rpm.

The choice of these machines is due to the simplicity of the form of the samples for testing. The tests were carried out in a motor oil environment with antifriction and antiwear additives, motor oil of class 10w40 (API SG / CD standard) was used. The test scheme is shown in Fig. 3.

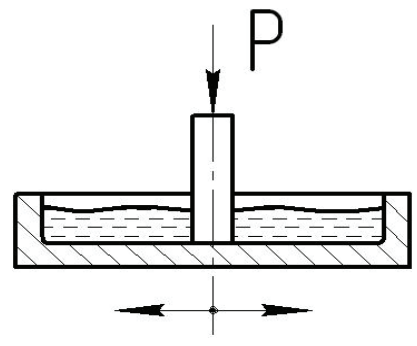

$a$

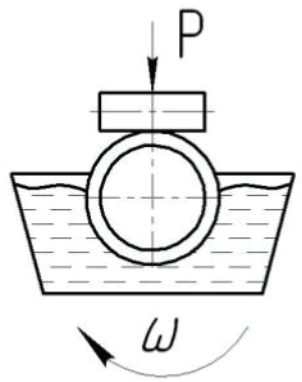

$b$
Fig. 3. Test scheme: a - translational type; b - rotation type.

As the samples were chosen square plates with

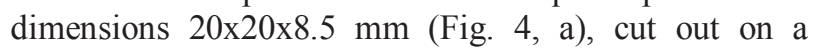
milling machine made of steel rolled products with a section of 30x30 mm. Scheme for cutting samples with a given exit angle of macrostructure fibers in Fig. 4, b.
Samples would be cut at different angles: $0^{\circ}, 15^{\circ}, 30^{\circ}$, $45^{\circ}, 60^{\circ}, 75^{\circ}, 90^{\circ}$. Sample material steel 45 was chosen as the material for samples. The choice of steel 45 is due to the fact that it is one of the materials for the production of crankshafts obtained by hot stamping technologies. The choice of a rolled rod for making samples allows one to determine the fiber direction of the macrostructure in the samples. The material of the pin, which causes abrasive wear, is also steel 45 . The roughness of the samples and the pin is $\mathrm{Ra} 1.25$ (grinding).

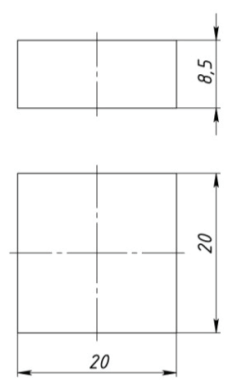

$a$

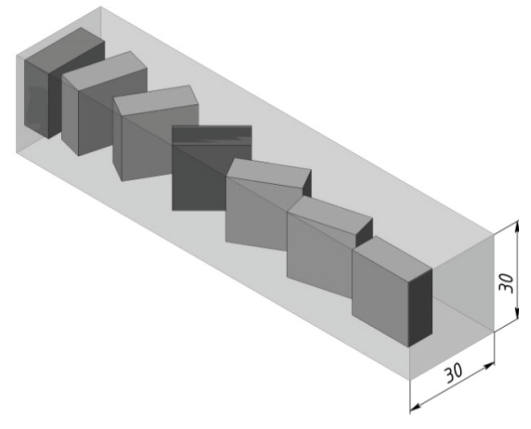

$b$
Fig. 4. Sample and methods for obtaining it: $a-$ sample size; $b$ - scheme for cutting samples.

\section{Experiments}

\subsection{Carrying out the experiment on a machine of translational type}

To fix the sample on the friction machine of the translational type, a special device (Fig. 5) was prepared in the plate form with a square cut for the sample. A $28 \mathrm{x}$ 96 transition plate is necessary to reduce the size of the sample. Otherwise, the samples with a different exit angle of the macrostructure fibers would have to be cut out of hot-rolled steel with a section of $100 \times 30 \mathrm{~mm}$.

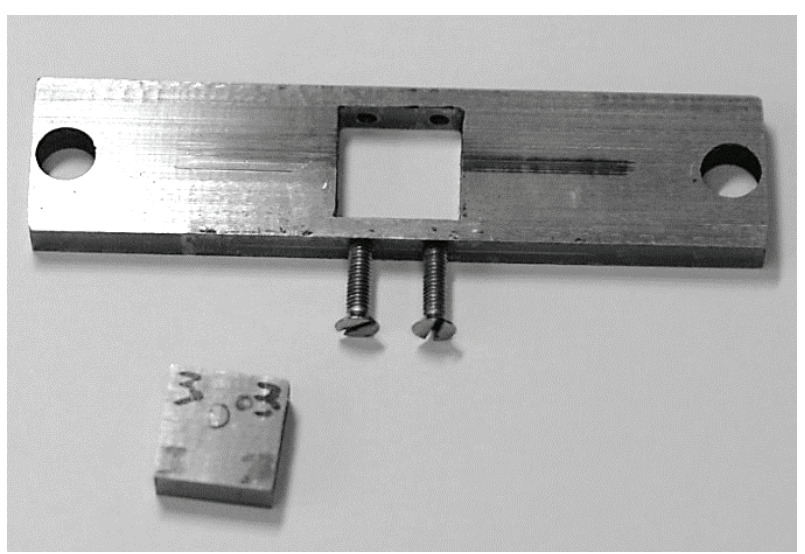

Fig. 5. Special device to fix the sample.

The samples were placed on a test machine (Fig. 6), the test mode and the load were set. The following test parameters were chosen: load - 15 loads $(2100 \mathrm{~N})$, test time - 3 hours, number of double strokes per minute -47 . Motor oil for testing was applied only at the initial time, 
simulating critical wear. Wear was evaluated by measuring the mass of the sample before and after the experiment.

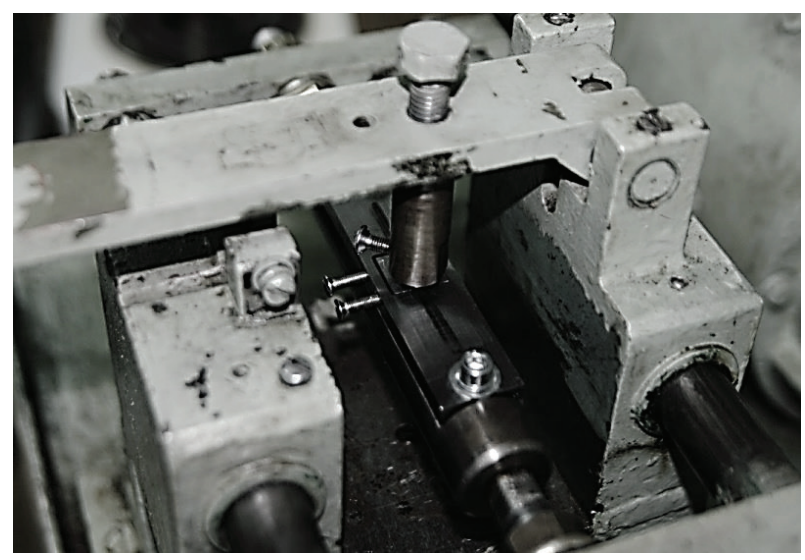

Fig. 6. Experiment on friction machine.

Mass measurements of the sample were carried out on an analytical balance Cubis MSA225S-100DI. The graduation mark of weights - $0,01 \mathrm{mg}$, accuracy class according to GOST R 53228-2008 - I. To reduce the measurement error, each weighing was performed 3 times.

\subsection{Carrying out the experiment on a machine of rotation type}

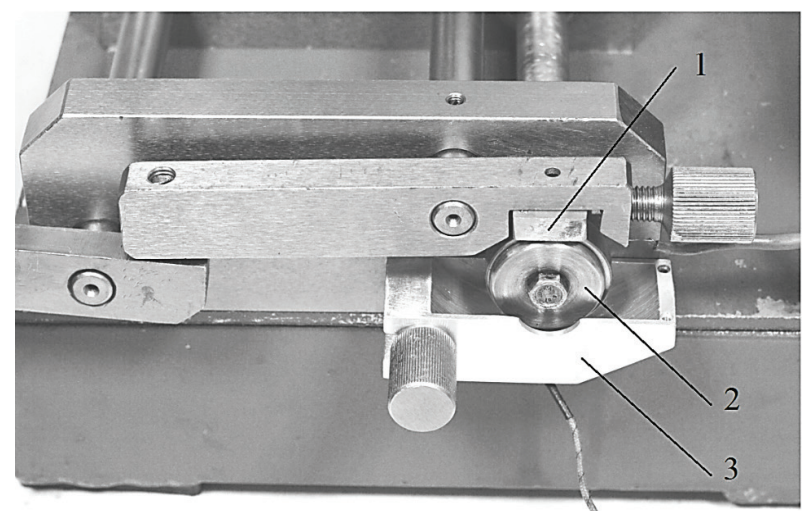

Fig. 7. Fixing the sample in the friction unit: 1 - sample; 2 disk; 3 - bath for oil.

Samples were installed on a test machine (Fig. 7), the test mode and the load were set. The following test parameters were selected: load - 4 and 5 loads (560-700 $\mathrm{N})$, test time - 6 minutes with 5 loads, 11 minutes with 4 loads. The test oil was poured into the bath to a level. Wear was evaluated similarly to the previous experiment.

\section{The results of the experiments}

The results of the experiments are tabulated (Table 1, 2, 3 ) and a plot of $\Delta \mathrm{m}$ (difference in mass before and after abrasion) is plotted on the exit angle of the macrostructure fibers on the sample surface (Fig. 8,9).
Table 1. Results of the experiment 1. Abrasive wear on a machine of translational type. 15 loads, 180 minutes.

\begin{tabular}{|c|c|c|c|c|}
\hline № & $\begin{array}{c}\text { Exit angle } \\
\text { of fibers, }\end{array}$ & $\begin{array}{c}\text { Mass before } \\
\text { abrasion, g }\end{array}$ & $\begin{array}{c}\text { Mass after } \\
\text { abrasion, g }\end{array}$ & $\Delta \mathrm{m}, \mathrm{mg}$ \\
\hline 1 & 0 & 22,200120 & 22,197902 & 2,218 \\
\hline 2 & 15 & 22,133115 & 22,130817 & 2,298 \\
\hline 3 & 30 & 21,691490 & 21,687977 & 3,513 \\
\hline 4 & 45 & 21,745010 & 21,739950 & 5,060 \\
\hline 5 & 60 & 20,498097 & 20,491811 & 6,2867 \\
\hline 6 & 75 & 20,796477 & 20,798874 & 7,6067 \\
\hline 7 & 90 & 20,386467 & 20,378361 & 8,1067 \\
\hline
\end{tabular}

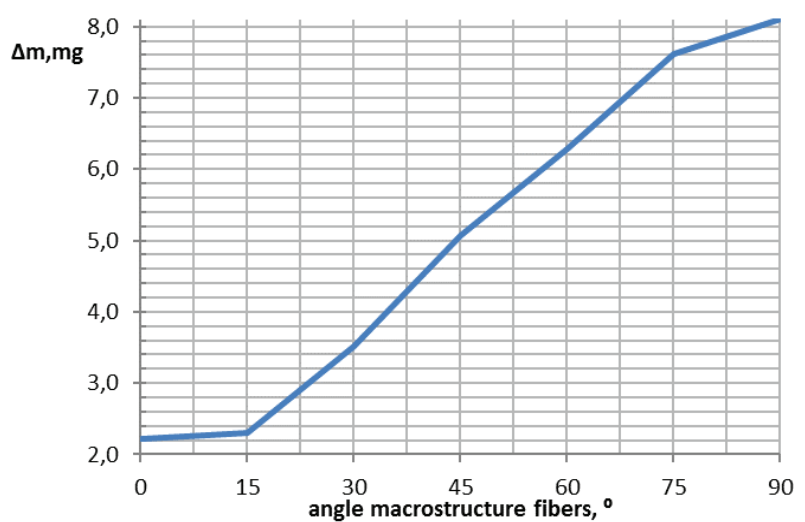

Fig. 8. Graph of dependence of $\Delta \mathrm{m}$ on the yield angle of macrostructure fibers for the experiment on a machine of translational type.

Table 2. Results of the experiment 2. Abrasive wear on a machine of rotation type. 4 loads, 11 minutes.

\begin{tabular}{|c|c|c|c|c|}
\hline № & $\begin{array}{c}\text { Exit } \\
\text { angle of } \\
\text { fibers, }^{0}\end{array}$ & $\begin{array}{c}\text { Mass before } \\
\text { abrasion, g }\end{array}$ & $\begin{array}{c}\text { Mass after } \\
\text { abrasion, g }\end{array}$ & $\Delta \mathrm{m}, \mathrm{mg}$ \\
\hline 1 & 0 & 22,1646410 & 22,16068667 & 3,9533 \\
\hline 2 & 15 & 22,1569223 & 22,15326521 & 3,7667 \\
\hline 3 & 30 & 22,15692009 & 22,15233333 & 4,5867 \\
\hline 4 & 45 & 22,15233333 & 22,14766667 & 4,6667 \\
\hline 5 & 60 & 20,2024401 & 20,19751333 & 4,9267 \\
\hline 6 & 75 & 20,4988112 & 20,4910902 & 7,7200 \\
\hline 7 & 90 & 20,7945721 & 20,78317333 & 11,3967 \\
\hline
\end{tabular}


Table 3. Results of the experiment 3. Abrasive wear on a machine of rotation type. 5 loads, 6 minutes.

\begin{tabular}{|c|c|c|c|c|}
\hline № & $\begin{array}{c}\text { Exit } \\
\text { angle of } \\
\text { fibers, }\end{array}$ & $\begin{array}{c}\text { Mass before } \\
\text { abrasion, g }\end{array}$ & $\begin{array}{c}\text { Mass after } \\
\text { abrasion, } g\end{array}$ & $\Delta \mathrm{m}, \mathrm{mg}$ \\
\hline 1 & 0 & 20,5518901 & 20,54634667 & 5,5433 \\
\hline 2 & 15 & 22,1276500 & 22,12146667 & 6,1833 \\
\hline 3 & 30 & 22,1777113 & 22,1708607 & 6,8500 \\
\hline 4 & 45 & 18,7643001 & 18,757120 & 7,1800 \\
\hline 5 & 60 & 21,1643612 & 21,15666333 & 7,6967 \\
\hline 6 & 75 & 20,7880202 & 20,77521333 & 12,8067 \\
\hline 7 & 90 & 20,3783611 & 20,36505333 & 13,3067 \\
\hline
\end{tabular}

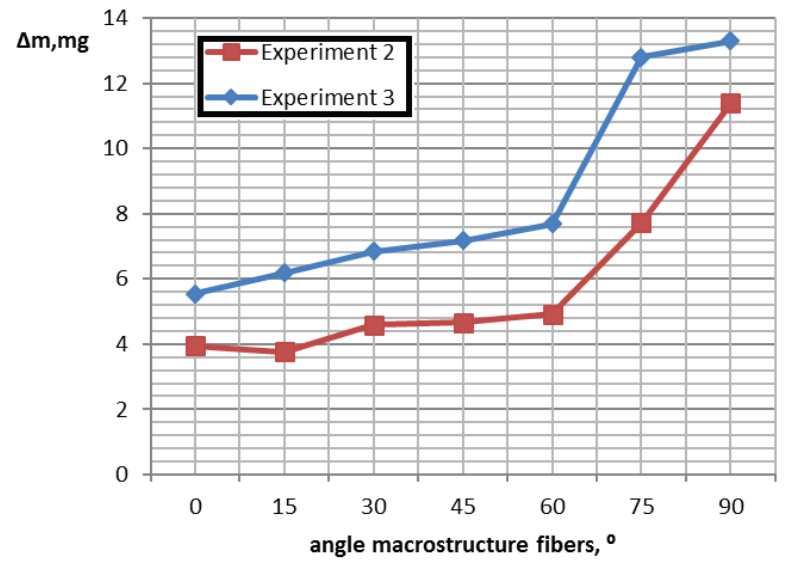

Fig. 9. Graph of dependence of $\Delta \mathrm{m}$ on the yield angle of macrostructure fibers for the experiment on a machine of rotation type.

According to the graphs presented, it can be seen that wear increases with an increase in the exit angle of the macrostructure fibers.

We should note that the on graph of the experiment 1 (Fig. 8) we observe 2 smoothed regions: in the corners area $0^{\circ} \ldots 15^{\circ}$ and in the corners $75^{\circ} \ldots 90^{\circ}$. In the range of angles from $0^{\circ}$ to $15^{\circ}$ there is an insignificant increase in wear of $27.4 \% \ldots 28.3 \%$ of the maximum wear $(8.106$ $\mathrm{mg})$. Therefore, when stamping forgings with an exit angle of the macrostructure fibers to contact surfaces in the range $0^{0} \ldots 15^{\circ}$, we obtain a minimal wear on these surfaces with progressive wear, which increases the working life of the part. Nevertheless, the nature of the graphs indicates that the wear process for the translational and rotational motion is different. In the forward motion, the dependence of wear on the fiber exit angle increases continuously (Fig. 8), with rotational motion (Figure 9) - the graphs have an explicit inflection point at an angle of $60^{\circ}$, after which wear rises sharply. Also, the graphs of experiments 2 and 3 (Fig. 9) do not contain smoothed regions. This does not contradict the assumption that the range of angles from $0^{\circ}$ to $15^{\circ}$ is the most preferable and there is minimal wear.

\section{Conclusions}

1. As a result of the conducted research, it was revealed that the exit angle of the macrostructure fibers to the contact surface significantly affects the wear process of the working surfaces of the parts.

2. The process of wear differs for translational and rotational motion.

3. The maximum wear occurs at the most unfavorable angle of $90^{\circ}$; the least wear is at an angle of $0^{\circ}$. The wear at an angle of $90^{\circ}$ is 3.65 times greater than at an angle of $0^{0}$ for translational motion. The maximum wear is 2.4 times the minimum for a rotational movement.

4. In the range of angles from $0^{0}$ to $15^{\circ}$, there is an insignificant increase in wear. After reaching the angle of $60^{\circ}$, a significant increase in wear values occurs depending on the fiber exit angle. Proceeding from this range from $60^{\circ}$ to 90 is undesirable for ingots obtained by hot stamping.

5. For forward motion at the top of the graph after reaching $75^{\circ}$, the rate of increase in wear values decreases. At an angle of $75^{\circ}$, wear is $93.8 \%$ of the maximum value.

6. Therefore, it is recommended to design processes of hot stamping so that the exit angle of the macrostructure of the fibers to the contact surface ranged from $0^{\circ}$ to $15^{\circ}$.

This scientific research is supported by the Foundation for the Promotion of Small Forms of Enterprises in the Scientific and Technical Sphere under the program "UMNIK" on the theme "Development of the technological process of cross-wedge rolling of the blank for hot stamping of the crankshaft in order to improve the mechanical properties" under contract No. $11294 \mathrm{GU} / 2016$ of 04/07/2017.

\section{References}

1. M.P. Kozochkin, A.N. Porvatov, J. of Frict. and wear 5, 389 (2014)

2. E.I. Semenov, O.A. Belokurov, V.Ju. Lavrinenko, Blank prod. in mech. Engineering 5, 28 (2005)

3. M.G. Allenov, O.A. Belokurov, Eng. J.: Sc. and Inn., 10, http://engjournal.ru/articles/1422/1422.pdf (2015)

4. E.I. Semenov, O.A. Belokurov, V.Ju. Lavrinenko, Mech. of def. body and met. working with pressure, 1, 55 (2001)

5. M.G. Allenov, O.A. Belokurov, Bull. of MSTU Stankin, 4, 67 (2016) 